\title{
Avances y retos en el campo de la Radiómica y Radiogenómica
}

Autor: Dra. Elvira Contreras de Miguel

Tutor: Dr. Fernando Ruiz Santiago

\section{Máster Universitario Oficial Avances en \\ Radiología Diagnóstica y Terapéutica y Medicina} Física

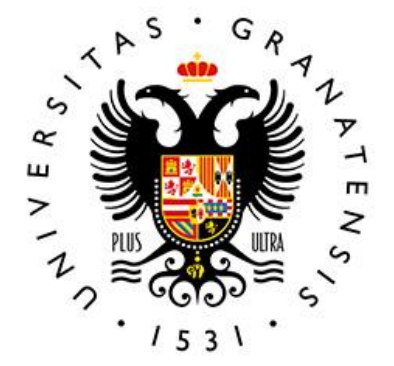

UNIVERSIDAD

DE GRANADA

Curso 2018-2019 


\section{RESUMEN}

Desde hace tiempo ha surgido una nueva dirección en la investigación del cáncer que se centra en la relación entre:

- Radiómica: se basa en convertir las imágenes médicas a una dimensión superior de datos para crear una hipótesis y mejorar el soporte diagnóstico, pronóstico y previsión de respuesta a tratamientos

- Radiogenómica o genómica de imágenes: basada en que las imágenes biomédicas son producto de una alteración molecular y genética a nivel celular.

Como tal, los parámetros de imagen derivados del procesamiento y análisis de imágenes avanzados pueden reflejar las bases moleculares y genotípicas del tejido tumoral. En oncología, la radiogenómica puede permitir una caracterización y comprensión más profundas de la biología del tumor en su totalidad, incluida la captura de la heterogeneidad intrínseca del tumor que puede impulsar el desarrollo del tumor.

El objetivo de la radiogenómica es desarrollar biomarcadores de imágenes que incorporen características fenotípicas y genotípicas que puedan predecir el riesgo y los resultados del paciente y, por lo tanto, estratificar a los pacientes según riesgos, para una atención terapéutica más precisa.

Pero, por otro lado, hasta ahora, la mayoría de los estudios disponibles de radiómica y radiogenómica, son retrospectivos y presentan cohortes de pacientes pequeños y las conclusiones que pueden extraerse son algo limitadas para la práctica clínica.

Se han realizado investigaciones con diferentes tipos de cáncer siendo las más relevantes:

1) En cáncer de mama: Se ha evidenciado el potencial de asociación entre el tipo de realce en las secuencias dinámincas de la resonancia magnética con contraste de mama y los subtipos moleculares Luminal A, Luminal B y Oncotype DX.

2) En el cáncer de pulmón se ha observado correlación entre los fenotipos moleculares relacionados con la mutación del EGFR (receptor factor crecimiento epidérmico) y algunos hallazgos de imagen en tomografía computarizada.

3) Glioblastoma multiforme (GBM): han permitido una predicción clínica y molecular no invasiva. 


\section{ABSTRACT}

In recent years, a new direction in cancer research has emerged that focuses on the relationship between:

-Radiomics refers to the conversion of digital medical images to higher dimensional data and the subsequent mining for hypothesis generation and/or testing and ultimately an improved decision support

-The principle of radiogenomics is that biomedical images are the product of processes occurring at the genetic and molecular level. As such, imaging parameters derived from advanced image processing and analysis can reflect the underlying molecular and genotypic basis of the tissue in oncology, radiogenomics can enable a deeper characterization and understanding of tumor biology in its entirety, including capturing the intrinsic tumor heterogeneity that can drive tumor development

The goal of radiogenomics is to develop imaging biomarkers incorporating both phenotypic and genotypic metrics that can predict risk and patient outcomes and thereby better stratify patients for more precise therapeutic care.

On the other hand, most of the available, radiogenomics and radiomics studies, are retrospective and feature small patient cohorts $(<100)$, and therefore the conclusions that can be drawn are somewhat limited for clinical practice.

Radiogenomic approaches in breast cancer, it has been showed the potential association between imaging and genomics by discovering a relationship between semi-automatically extracted imaging features describing MRI enhancement dynamics with Luminal $A$ and Luminal B subtypes and Oncotype DX.

In lung cancer have showed a correlation between molecular phenotypes, EGFR mutation, and some imaging traits in lung computed tomography.

In GBM have the potential to predict clinical and molecular characteristics of tumors noninvasively 


\section{AGRADECIMIENTOS}

Al Dr. Ruiz Santiago por su paciencia con mi inexperiencia y sus grandes consejos para ordenar mis ideas.

A Joaquín, mi marido y a mis padres, por todo lo que me ha ayudado y animado con este proyecto.

A mis amigos Alma y Tomás, por introducirme en los modelos matemáticos y dimensión fractal. 


\section{INDICE PAGINADO}

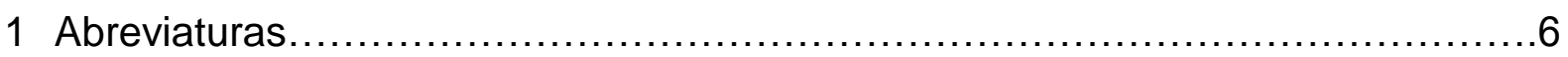

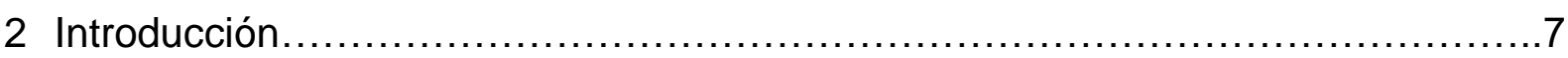

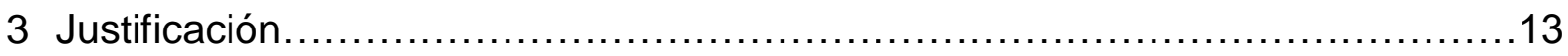

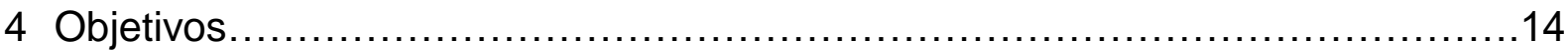

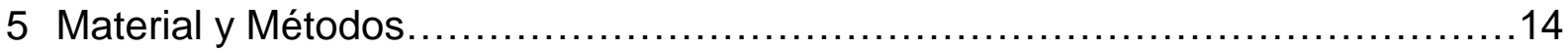

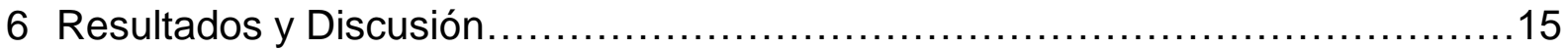

6.1 Radiómica y radiogenómica en el cáncer de mama...................... 15

6.2 Radiómica y radiogenómica en el cáncer de pulmón.......................28

6.3 Radiómica y Radiogenómica en el Glioblastoma multiforme.................34

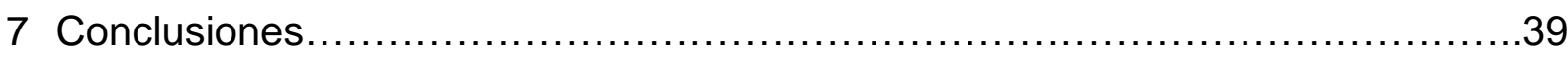

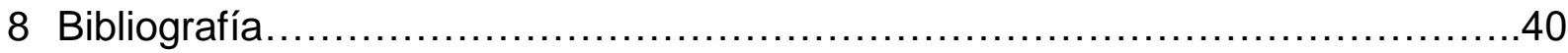




\section{1-ABREVIATURAS}

-BCRA 1 Y 2: Breast Cancer type 1/ type 2: gen supresor de tumores que codifica una proteína BCRA 1 y 2.

-BIRADS: Breast Imaging Reporting and Data system.

-TC: tomografía axial computarizada.

-EGFR: receptor del factor de crecimiento epidérmico.

-GMB: glíoblastoma multiforme.

-GLCM: grey level con-occurrence matrix (matriz de nivel de concurrencia del gris).

-GLRL: grey level run length (nivel ejecución gris).

-HER 2: receptor 2 del factor de crecimiento epidérmico humano.

-IA: Inteligencia artificial.

-IMC: Índice de masa corporal.

-RE: receptores estrógenos.

-RM: resonancia magnética.

-RP: receptor progesterona.

-TCGA: El atlas del genoma del cáncer (The cancer Genoma Atlas).

-TCIA: El archivo de imágenes del cáncer (The Cancer Imaging Archive).

-TN: triple negativo. 


\section{2-INTRODUCCIÓN}

La inteligencia artificial (IA) se basa en algoritmos asistidos por ordenador, sistemas que pueden realizar, con una alta precisión, inferencia de una gran cantidad de datos de conocimiento, permitiendo desarrollar un aprendizaje automático en grandes bases de datos de imágenes (1). El desarrollo de técnicas de imágenes médicas totalmente digitales ha generado imágenes de alta calidad y con una amplia diversidad de la información. Además, en los últimos años, se están desarrollando los biomarcadores de imagen como expresión de esta sinergia entre las imágenes digitales y su procesado asistido por ordenador. Estos procedimientos innovadores extraen de las imágenes médicas una información cuantitativa que no puede detectarse ni medirse visualmente en las imágenes originales (2), así la Radiómica analiza numerosas imágenes médicas para extraer una gran información de ellas, generando una hipótesis, mejorando el apoyo diagnóstico y relacionando dichas características con el pronóstico del paciente para realizar una medicina de precisión (3).

Tras el auge de la IA, la Radiómica, surge como una técnica novedosa para resolver problemas de la medicina de precisión, dado que se puede realizar en base a imágenes médicas multimodales, de forma no invasiva, más rápidas y con un bajo coste (1). Se ha visto que dentro de un mismo tumor puede existir una heterogeneidad que con una sola biopsia no se podrían analizar. La Radiómica podría solventar dicho problema, mejorando la accesibilidad a ciertas localizaciones, como los tumores cerebrales y evitando las complicaciones indeseables causadas de las biopsias. Por otro lado, muchos biomarcadores de imágenes basados en la Radiómica pueden ser útiles como apoyo diagnóstico, para evaluar la severidad y estimar la supervivencia global y el intervalo libre de enfermedad (1).

La Radiómica es una nueva palabra derivada de la combinación de" radio" qué significa imagen radiológica y "ómica" se refiere a las tecnologías colectivas que exploran los roles, relaciones y acciones de varios tipos de moléculas dentro de las células de un organismo con el fin de definir e interrogar el epigenoma, transcriptoma, proteoma, o metaboloma en su totalidad. Las tecnologías "ómicas" de alto rendimiento crean "big data", con una 
diversidad y una complejidad que requieren nuevas arquitecturas, algoritmos y análisis para gestionarlos, extraer valores y conocimientos ocultos de ella $(1,3)$.

Lo primero que requiere la Radiómica es la identificación del volumen de interés del tumor y posteriormente, con métodos automáticos o semiautomáticos realizan la segmentación del tumor. A continuación, se adquieren múltiples características cuantitativas de esa zona de interés tumoral, que o bien solas o combinadas con la clínica y los datos patológicos, desarrollan modelos para predecir tanto la supervivencia como respuesta al tratamiento.

En cuanto al término "RADIO" se realizan una serie de análisis a la imagen, basada en la extracción de la imagen de los tumores segmentados en imágenes de RM o TC para obtener las características radiómicas de la imagen:

A. Descriptores morfológicos: forma, volumen y área de superficie

\section{B. Descriptores Estadísticos}

B1: Primer orden: características del histograma como la entropía y energía, los más importantes, media, mediana, desviación estándar, kurtosis, skewness (oblicuidad), uniformidad y varianza en la valoración de atenuación de los pixeles del tumor.

Nos aportan información de la progresión o crecimiento tumoral.

B2: Orden superior: Textura. Se usa para reflejar la textura de las características del tumor, valorando la escala de grises:

-GLCM: grey level co-occurrence matrix (matriz de nivel de concurrencia del gris)

-GLRL: grey level run length (nivel ejecución gris)

Están asociadas con el estadio tumoral, metástasis, respuesta a tratamiento y supervivencia.

C. Descriptores Regionales: expresa heterogeneidad intratumoral, un importante factor pronóstico del paciente.

D. Descriptores Basados en modelos matemáticos: dimensión fractal basado en la forma intrínseca de un objeto, para así diferenciar la agresividad del tumor, sobre todo usado en el cáncer de pulmón (4)

E. Descriptores Cinéticos: basada en los cambios con la captación de contraste en los voxels.

E.1 Cinética de la curva: Incluyen el máximo contraste de realce, tiempo para alcanzar el pico, índice de captación, índice de lavado, forma de la curva, realce en primer punto de 
contraste, ratio de realce de intensidad de la señal, tasa de variación total y la variación de la tasa total normalizada

E.2: Cinética de variación del realce: máximo realce, tiempo pico, tasa de varianza creciente y decreciente (5).

Tras obtener todas estas características, con análisis estadísticos y asistidos por ordenador, se clasifican a los pacientes y se predicen los pronósticos y resultados de los tratamientos.

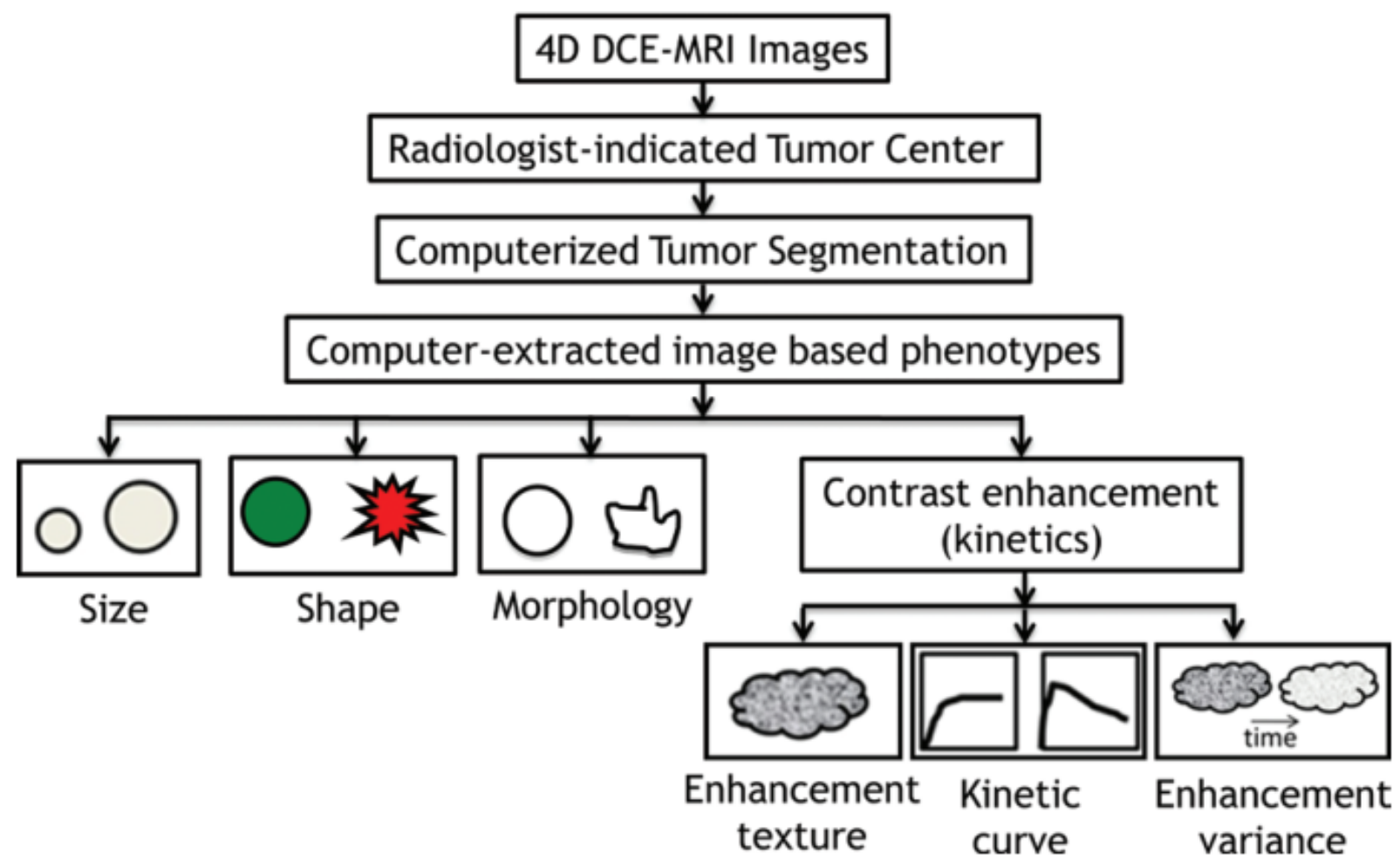

Figura 1: Esquema que ilustra la extracción asistida por ordenador de los descriptores cuantitativos del tumor basados en las secuencias dinámicas con contrastes de RM (5). 
En cuanto a la "ÓMICA" se incluyen:

$\left.1^{\circ}\right)$ Proteómica: Estudio sistemático completo de las proteínas del organismo. Se ha centrado en descubrir y validar biomarcadores proteicos para predecir y pronosticar varias enfermedades (3).

$2^{\circ}$ ) Metabolómica: Es el campo más joven de la "ómica" pero que ha ganado gran protagonismo dado que estudia y cuantifica sistemáticamente todos los productos metabólicos de la una célula, tejido, organismo, fluidos biológicos u organismo en un punto específico en el tiempo (3).

El término de metaboloma se refiere a la dinámica de los metabolitos qué representan la totalidad de las células que forman el organismo en determinadas condiciones. Se ha visto que en casi la mayoría de los cánceres se altera el metabolismo celular. La RM espectroscopia utiliza las propiedades del campo magnético de diferentes núcleos atómicos y puede determinar la estructura orgánica de los componentes, así que se utiliza para determinar la estructura del carbono 13 (3).

También se ha visto, que las características fenotípicas en las imágenes médicas pueden resultar de la expresión del genotipo. Así nace la Radiogenómica, que pretende correlacionar imágenes con genes subyacentes, mutaciones y patrón de expresión (3). La Radiogenómica puede proporcionar información genética de voxel por voxel para un tumor heterogéneo completo o, en el contexto de metástasis o conjunto de tumores y, por lo tanto, ser guía de terapia adaptada (3).

El principio subyacente de la Radiogenómica es que las imágenes biomédicas son el producto de procesos que ocurren a nivel genético y molecular. El objetivo de la radiogenómica es desarrollar biomarcadores de imagen incorporando fenotípicos y alteraciones genotípicas que pueden predecir el riesgo y los resultados. Y por lo tanto, estratificar mejor a los pacientes para una terapéutica más precisa (3).

En la pasada década se hizo principal hincapié en el atlas del genoma del cáncer (TCGA) qué ha facilitado una caracterización molecular mucho más profunda y ha definido subgrupos y marcadores biológicos para identificar las dianas terapéuticas. 
La radiogenómica se centra en el estudio de la imagen y posteriormente en la Genómica y transcriptomica:

- Genómica es el estudio sistemático de la secuencia del DNA o genoma en el organismo. La medicina genómica implica la exploración de los caminos moleculares de los marcadores genómicos y la interacción entre el genoma con otros factores como el ambiente o el estilo de vida y la aplicación de la información del genoma para predecir y tratar las enfermedades

- Transcriptómica: estudio del ARN presente en células, tejidos u órganos que nos permite comprender la diferencia en la expresión genética, entre pacientes sanos y enfermos. Estudiando los genes activados y desactivados en grupos de pacientes, se analiza cómo la expresión genética puede afectar a la progresión de la enfermedad. Un ejemplo de esto es el estudio de la expresión de los arrays para el realizar la tipificación del cáncer de mama, en función de recomendaciones de tratamiento en la práctica clínica (MAMA PRINT y Oncotype DX) $(3,5)$

Se ha visto en los estudios, que las mutaciones genéticas pueden determinar rasgos en las neoplasias que se pueden asociar con el pronóstico de los pacientes. Se podría estratificar al paciente usando los biomarcadores radiómicos que contenga la información acerca de las características del tumor (mutación, angiogénesis, metástasis y escape inmunológico) determinando el pronóstico del paciente (supervivencia, recurrencia, toxicidad) acorde a varias estrategias terapéuticas (3). 


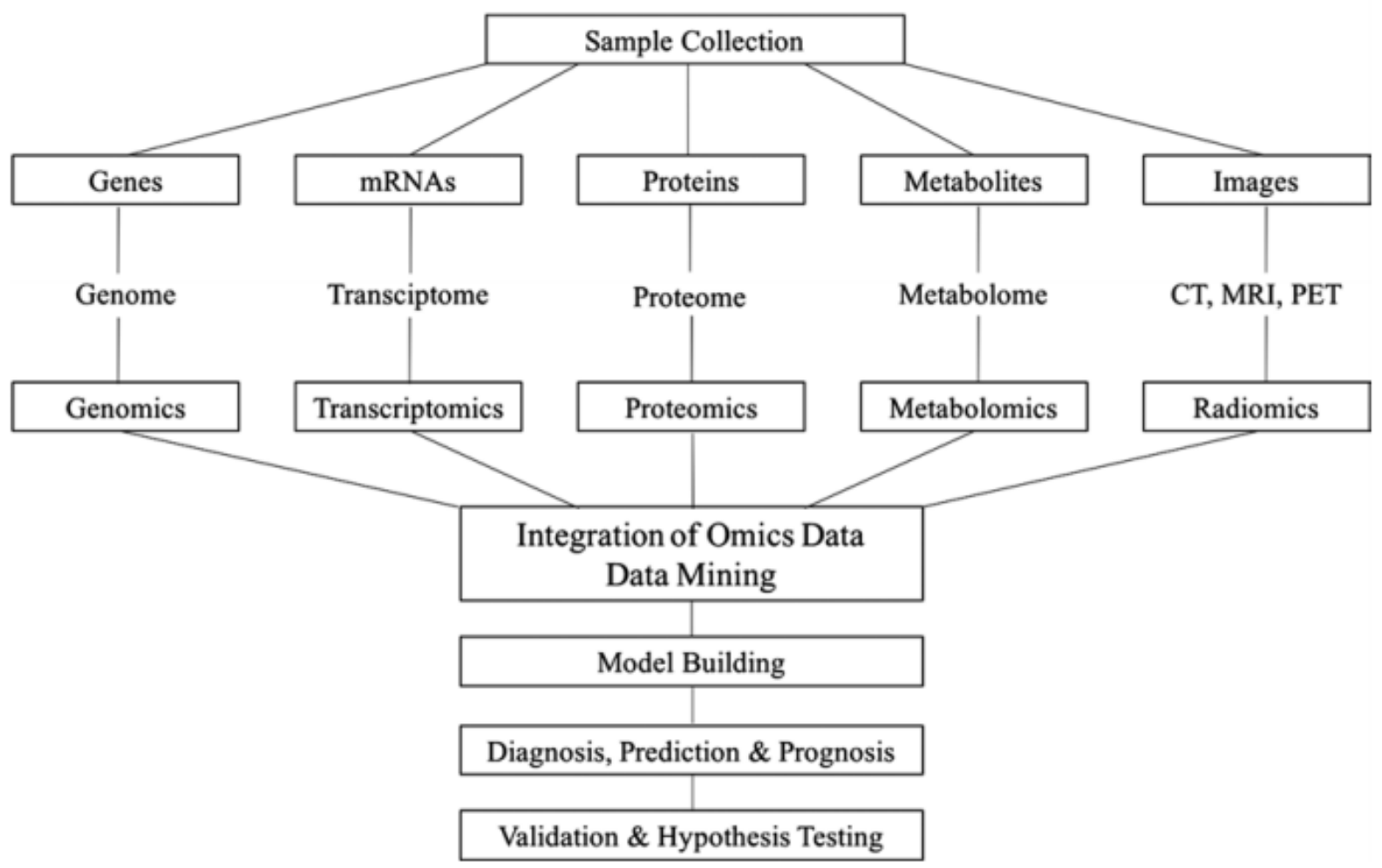

Figura 2: Diagrama que muestra la aproximación diagnóstica a los sistemas biológicos y pronósticos de las neoplasias. El análisis de los marcadores "ómicos" de invasión tisular e integración con la imagen en el conjunto de datos "ómicos", permite la extracción de datos, la construcción de modelos y posteriormente el aumento de la precisión diagnóstica, evaluación pronóstica y la predicción de la respuesta terapéutica (3). 


\section{3-JUSTIFICACIÓN}

El cáncer es una de las patologías más prevalentes en nuestros días y uno de los mayores campos de investigación.

El tema de la Radiogenómica y Radiómica me parece sumamente interesante, desde el punto de visto radiológico y clínico.

La aplicación de la inteligencia artificial aplicada en la medicina creo que ha sido un avance muy importante. Estos procedimientos innovadores extraen de las imágenes médicas una información cuantitativa, llamados biomarcadores, a base de algoritmos 0 sistemas informáticos (1), que no puede detectarse en las imágenes originales. Utilizar dichos biomarcadores, nos va a permitir a los radiólogos cambiar el concepto y los procesos de nuestro trabajo, abriendo el campo de la imagen médica tradicional a otras disciplinas como la ingeniería, la física y las matemáticas (2).

En los tiempos en que nos encontramos me parece de vital importancia realizar una medicina de precisión que implica un enfoque de sistemas biológicos, mediante un estudio complejo, con modelos informáticos y matemáticos, que valoran la interacción de genes, metabolitos, proteínas, elementos reguladores y otros componentes biológicos. Se ha de realiza un "enfoque holístico para descifrar la complejidad de los sistemas biológicos", dado que se parte de la base de que la totalidad que forma la vida de los organismos es más que la suma de sus partes. Frente esta nueva concepción, está la ciencia tradicional que en gran medida es impulsada por hipótesis y necesariamente reduccionista.

En el momento actual el cáncer de pulmón y el cáncer de mama son las neoplasias más frecuentes en los ambos géneros con alta mortalidad. Disponemos sólo de pruebas de imagen y diagnósticos invasivos, para su diagnóstico, estadiaje y pronóstico.

GBM es la neoplasia cerebral primaria maligna más frecuente en adultos, con escasa supervivencia que sólo se pude diagnosticar por la imagen y tipificar correctamente tras cirugía. Todo esto implica en algunos casos retraso en el diagnóstico y tratamiento, con repercusión sobre la clínica del paciente.

Con estas nuevas técnicas, se podrán realizar un tratamiento enfocado de la enfermedad y estrategias de prevención para grupos de individuos, según su enfermedad, genética, ambientes y estilos de vida (3). Se podrán evitar realizar biopsias, a veces limitadas por el acceso a zonas difíciles, evitando complicaciones y comorbilidades a los pacientes. 


\section{OBJETIVOS}

- Abordar el tema actual de la radiómica y radiogenómica en el cáncer de mama, pulmón y GBM.

- Hacer una búsqueda y selección de estudios relacionados con dichos temas.

- Hacer una interpretación de los estudios seleccionados basada en mi experiencia como radióloga y exponer hacia donde están apuntando los estudios más recientes.

\section{MATERIAL Y MÉTODO:}

El método empleado para llevar a cabo el Trabajo Fin de Máster ha sido una revisión bibliográfica por medio de bases de datos, monografías, revisiones sistemáticas y ensayos clínicos.

La revisión de la evidencia científica se ha realizado fundamentalmente en las bases de datos: Pubmed y Web of Science, con las siguientes limitaciones:

-límite de fechas: últimos 8 años

-idioma: inglés

-criterios de exclusión: estudios con errores y sesgos que pueden alterar los resultados -criterios de inclusión: se seleccionan artículos de mayor evidencia científica en el cuartil 1 y 2 , correctamente estructurados, con el un planteamiento lógico y siguiendo los criterios de la lectura crítica de artículos. Casi todos son estudios retrospectivos de cohortes salvo un estudio de cohorte prospectivo (9)

-Descriptores en inglés: radiomics and radiogenomics and breast cancer/ radiomics and radiogenomics and lung cancer, radiomics and radiogenomics and glioblastoma multiforme

-Operadores booleanos: "AND" y "OR". 


\section{RESULTADOS Y DISCUSIÓN}

Se encontraron los siguientes artículos:

-Radiomics OR Radiogenomics AND Breast cancer: 48

-Radiomics OR Radiogenomics AND Lung Cancer: 136

-Radiomics OR Radiogenomics AND Glioblastoma multiforme: 74

Lo siguiente consistió en realizar una lectura exhaustiva de los artículos y documentos encontrados, seleccionados y clasificados de acuerdo con los objetivos del estudio:

Se procesaron los datos provenientes de la revisión de la evidencia científica y realizando un análisis crítico exhaustivo clasificando los artículos e información según interés y objetivos del estudio.

Se describen a continuación, los avances en radiómica, radiogenómica, transcriptómica, proteómica y metabolómica de estos tres tumores.

\subsection{Radiómica y radiogenómica en Cáncer de mama:}

El estudio Radiómico del cáncer de mama, comienza con la extracción de información de las imágenes, analizando:

1) Descriptores morfológicos: tamaño y forma (asistido por el BIRADS).

2) Estadísticos:

a) Primer orden: Energía y Entropía.

b) Orden superior: Textura: Implica cuatro escalones;

i) Extracción: los cálculos se realizan en base a modelos estadísticos, estructurales y valores numéricos para cada textura.

ii) Discriminación de la textura: las imágenes son segmentadas en radiones con similar textura y características y son agrupadas juntas.

iii) Clasificación de la textura: grasa, fibroglandular, benigno o maligno

iv) Reconstrucción: en base a la información de las texturas. En radiogenómica, los resultados del análisis de la textura pueden correlacionarse con la genómica.

3) Descriptores regionales: nos informan sobre la heterogeneidad, relacionada en las investigaciones con el pronóstico.

4) Descriptores cinéticos: a partir del estudio dinámico con contraste. 


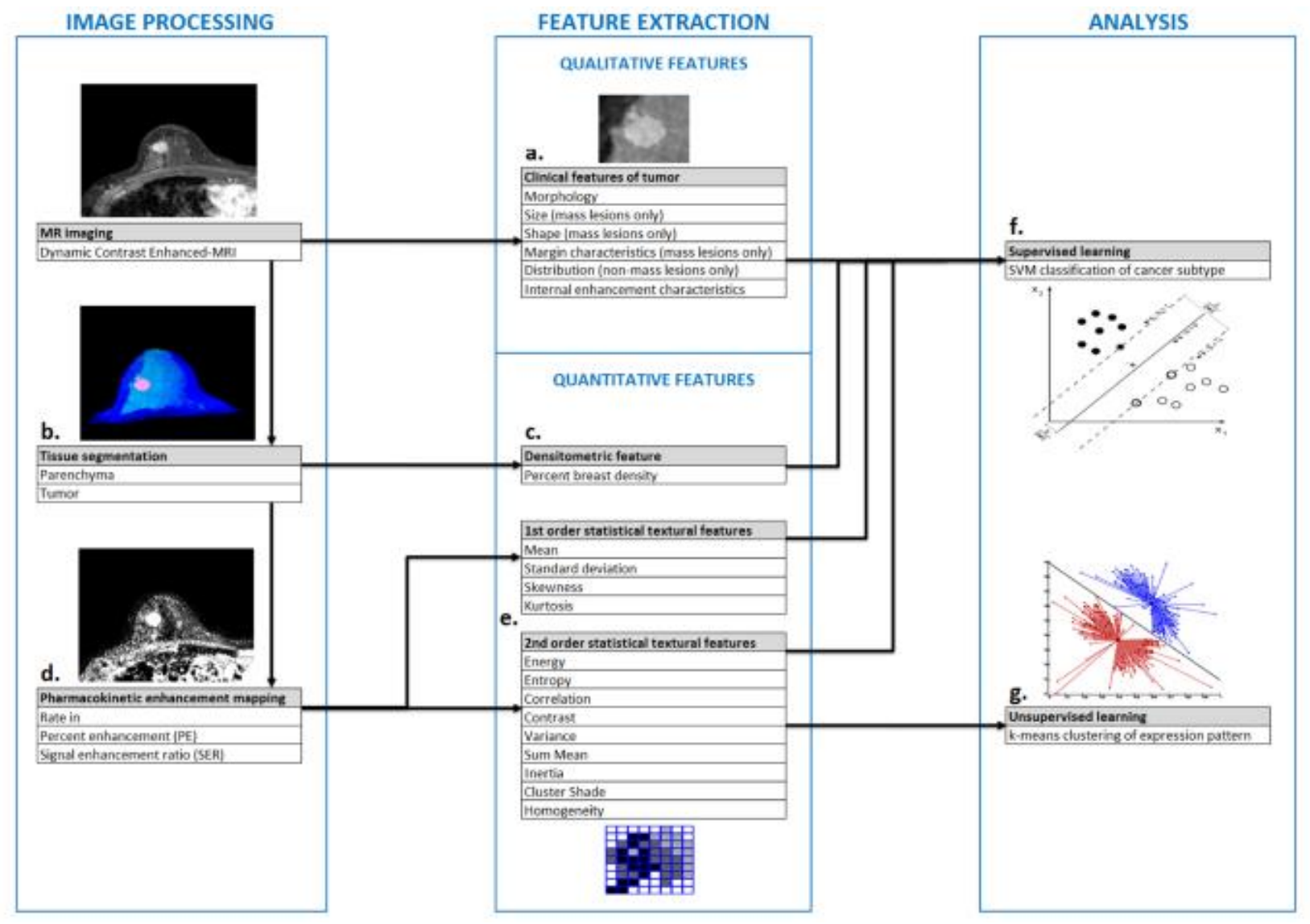

Figura №3: Resumen del análisis radiómico. (a) Las características clínicas fueron evaluados por radiólogos según el sistema BIRADS, directamente de imágenes de RM dinámica con contraste, analizado los descriptores morfológicos. (b) Imagen en 3D, con segmentación en compartimentos, con tumor en rojo y parénquima en azul, donde se evaluó la densidad (c). (d) Muestra los mapas de realce, a través de los cuales, se extraen las características de la textura (e) definiendo el realce heterogéneo, según los valores obtenidos. Posteriormente, tras analizar todos los datos, nos conducen hacia dos análisis usando las características extraídas y modelos de aprendizaje asistido por ordenador (13). 
En cuanto al apartado de la "OMICA":

-Genómica: Según Perou et al, clasificó los cánceres de mamá según la expresión genética, la herencia, micro RNA y niveles de proteínas, según el TCGA en 4 tipos:

1. Luminal A: pronóstico más favorable.

2. Luminal B: pronóstico intermedio.

3. Receptor tipo 2 del factor de crecimiento epidérmico Humano positivo (Her2): pronóstico desfavorable, pero con tratamientos diana que han mejorado su pronóstico en la actualidad.

4. Triple negativo o tipo basal: alto riesgo de recaída y si existe afectación linfática, el pronóstico es desfavorable sin importar el número de ganglios afectos.

\begin{tabular}{|c|c|c|c|c|c|c|}
\hline \multirow[b]{2}{*}{ Intrinsic Subtype } & \multicolumn{5}{|c|}{ Clinical-Pathologic Surrogate Definition } & \multirow[b]{2}{*}{ Recurrence Risk } \\
\hline & Subtype & ER & PR & HER2 & $\mathrm{Ki}-67$ & \\
\hline Luminal A & Luminal A-like & Positive $^{\dagger}$ & Positive & - & Low & Low (if available) \\
\hline \multirow[t]{2}{*}{ Luminal $\mathrm{B}^{\ddagger}$} & Luminal B-like (HER2 negative) $)^{\S}$ & Positive & Negative or low & - & High & High (if available) \\
\hline & Luminal B-like (HER2 positive) & Positive & Any & Overexpressed or amplified & Any & Not applicable \\
\hline ErbB2 overexpression & HER2 positive (nonluminal) & Absent & Absent & Overexpressed or amplified & Not applicable & Not applicable \\
\hline Basal-like & Triple negative (ductal)" & - & - & - & Not applicable & Not applicable \\
\hline
\end{tabular}

Tabla №1: Subtipos intrínsecos de cáncer de mama.

NOTA: ER: receptor de estrógenos, Erb-B2: Erb-B2 receptor de tirosin-quinasa, PR: receptor de progesterona, Her 2: receptor 2 del factor humano de crecimiento epidérmico. *Basado en ensayos de expresión de multigenes.

†El punto de corte de los valores del Ki67varían en función del laboratorio local, por ejemplo, si tiene una media de valora de Ki-67 del $20 \%$, valores del $30 \%$ o superiores se pueden considerar como altos y aquellos del $10 \%$ menores o bajos.

‡El tipo Luminal B-Like, incluye los cánceres que no tienen las características del tipo Luminal A. Tanto un valor alto de Ki-67 o bajo valor de RP se puede usar para diferenciar entre un Luminal A like de un Luminal B-like (Her2 negativo).

$\S R E$ positivos y Her2 negativo y al menos Ki-67 alto o RP negativos o bajos, se asocian con alto riesgo de recurrencia.

II Hay un $80 \%$ de superposición entre el subtipo TN y basal-like. Algunos casos con RE bajos pueden agruparse con subtipos no luminal en el análisis genético (3). 
Hay múltiples ensayos moleculares comercializados, como el Oncotype DX, Mamaprint, Mammostrat, PAM50, y EndoPredict. Sólo hay dos aprobados por la FDA, el OncotypeDX y el MamaPrint, que han resultado efectivos para evaluar el riesgo de desarrollar metástasis a distancia y predecir el beneficio de la quimioterapia adyuvante (3).

Dado que la biopsia de pequeñas regiones del tumor no es una muestra representativa de la genética y epigenética, se ha usado como alternativa la inmuhistoquímica, para la definición del subtipo molecular. Pero esta imprecisión puede llevar a infradiagnosticar cánceres más agresivos o sobrediagnosticar y sobretratar cánceres de mama indolentes.

Debido a estas limitaciones y el alto coste de los ensayos clínicos, hay una alta demanda para diseñar técnicas no invasivas y precisas para diferenciar los subtipos moleculares, lo que presenta una gran oportunidad para imágenes médicas avanzadas.

- Transcriptómica: La valoración del microRNA no codificante y la expresión del RNA mensajero mostraron ser superiores en la estadificación del riesgo en comparación con el Oncotype DX y el MamaPrint. La biopsia líquida permite diagnosticar de forma no invasiva los tumores utilizando el micro RNA circulante en sangre periférica. Se ha visto que las mutaciones somáticas, en el cáncer de mama, se producen en menos de un $10 \%$ de frecuencia y que ocurren en 3 genes TP53, PIK 3CA y GATA 3, mostrando una heterogeneidad inter e intratumoral, creando distintos subtipos de cáncer (5).

- Proteómica: Aunque la inmunohistoquimica es una técnica alternativa de excelente pronóstico en la práctica clínica, existen algunas limitaciones como es la fijación química y el análisis semicuantitativo. Métodos alternativos de análisis como los arrays proteicos y la espectroscopia de masa han tenido resultados prometedores, indicando que el análisis de la proteogenómica del cáncer de mama puede aportar información sobre mutaciones somáticas e identificar los genes con las regiones de delecciones o amplificaciones para identificar nuevas dianas terapéuticas.

- Metabolómica: El metabolismo celular es uno de los principales procesos que se afectan cuando las células se convierten en cancerígenas y se correlaciona con la progresión del tumor. En particular el metabolismo de la glucosa se altera con frecuencia en las células tumorales. Los tumores con receptores de estrógenos negativos tienen un elevado incremento de los intermediarios glucolíticos y glucogenolíticos debido al incremento de la glucolisis aeróbica; las mutaciones de TP53 se relacionan con niveles bajos de lípidos 
glicerofosfocolina; BCRA 1 se relaciona directamente con coenzima A, acetil coenzima A y glutatión. Recientes investigaciones que valoran la relación del metabolismo previo y posterior a la neoadyuvancia con la supervivencia, han demostrado que después del tratamiento hay una disminución de la glicerofosfocolina que se relaciona con mayor supervivencia a largo tiempo (3).

\section{Aplicaciones actuales:}

1) Diagnóstico de malignidad: La primera utilidad es para el diagnóstico de cáncer de mama. Se han demostrado algunas características Radiómicas en pacientes con mamas densas y mamografía negativa para cáncer, podría diferenciar el tejido mamario normal del tejido neoplásico. Otras características de la radiómica también se correlacionaron con tamaño tumoral, pero no con los factores pronósticos como son la: Energía, Entropía (descriptores estadísticos de primer orden) y disimilaridad (descriptores basados en modelos). La Entropía también se ha encontrado relación significativa con los receptores de estrógenos, importante para la elección del tratamiento hormonal. Está nueva información podría contribuir a una mejor comprensión del cáncer de mama través de imágenes y eventualmente puede contribuir a personalizar de adaptación de tratamientos individuales en la medicina de precisión (7).

El análisis de parénquima mamario contralateral, en la caracterización de los tumores de mama en la mamografía digital, a través de la radiómica cuantitativa, mejora la clasificación de las lesiones en vez de utilizar solamente las características del tumor. Así la combinación del parénquima y las características tumorales pueden proporcionar un modelo predictivo más fuerte de malignidad (6).

2) Recurrencia: Los estudios mostraron que el mayor tamaño tumoral y menor textura de realce (heterogeneidad) tenían mayor riesgo de recurrencia (4). Se hallaron diferencias significativas, en el análisis de regresión múltiples, basada en el subtipo tumoral (según tamaño y textura de realce) con MamaPrint, Oncotype DX y riesgo de recaída basado en subtipo y proliferación PAM50, respectivamente, con todos menos este último mostrando la diferencia estadística. 
Estos datos de la radiogenómica cualitativa y radiómica cuantitativa, nos indican que los descriptores de BI-RADS con mamografía y RM dinámica con contraste podrían ser posibles biomarcadores de imágenes de riesgo de recurrencia de cáncer de mama, junto con la densidad mamaria de predominio graso, masa mal delimitada y calcificaciones lineales ramificadas, en mamografía y masa espiculada en RM $(3,5,8)$.

A
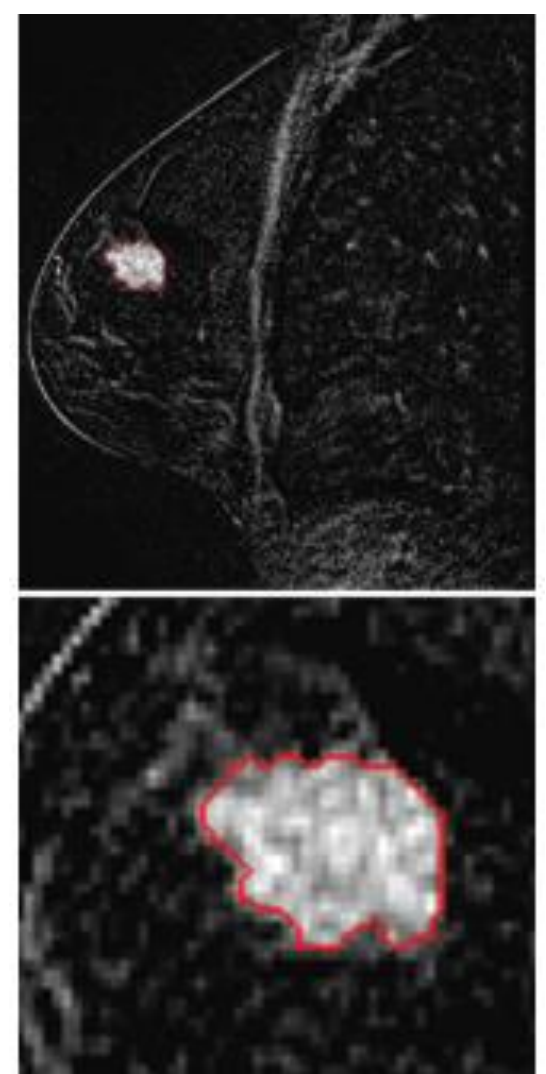

B
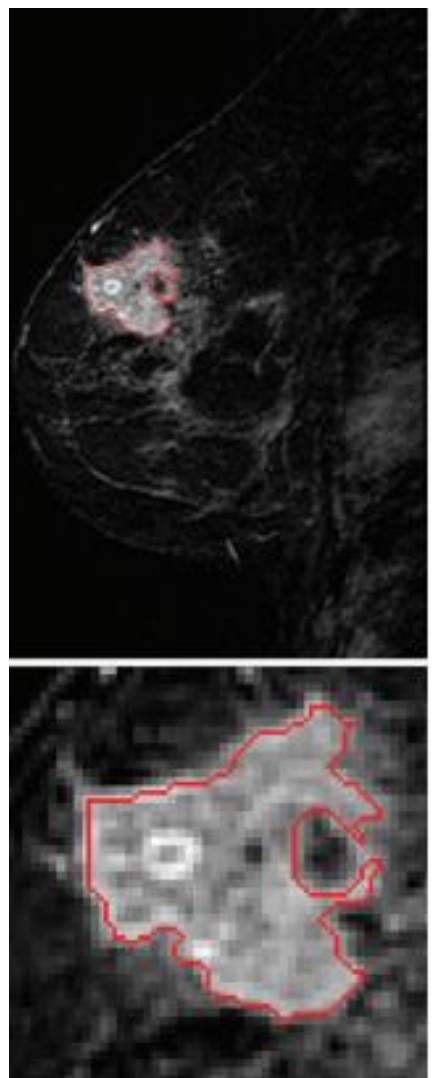

Figura N. 4: Las figuras A y B muestran ejemplos de secuencias de sustracción de RM de mama dinámica con contraste, un caso de un pronóstico potencialmente bueno (RE y RP positivos y Her 2 negativos, sin afectación ganglionar) y un caso de un pronóstico potencialmente malo (RE, RP y Her 2 negativos sin afectación ganglionar), junto con Las segmentaciones informáticas de los tumores primarios (5).

Parece ser que las pacientes con mama grasa, tienen una disregulación en el tejido adiposo y por lo tanto en su microambiente, se producen una aromatización de los andrógenos en estrógenos, que pude promover la recurrencia tumoral. 
Así mismo, cuando se clasifican las pacientes usando el estado menopáusico, hay una asociación significativa, entre baja densidad mamaria con elevada recurrencia en pacientes posmenopáusicas $(8,9)$.

Por otro lado, se realizó un estudio retrospectivo del enfoque radiómico basado en la RM preoperatoria para predecir la recurrencia. Se recogieron varias características: morfológicos y estadísticos del orden superior (textura), para crear una nueva firma radiómica, denominada rad-score, se calculó para cada paciente, que fue clasificado en un alto riesgo o bajo riesgo basado en la propia puntuación de Rad (9). Se evidenció que los altos Rad-escores, se correlacionaban con peores valores de supervivencia libre de enfermedad (SLE) y que la estimación de la SLE era más precisa cuando se incluían datos clinicopatológicos en la evaluación.

Druller et al propusieron una nueva firma radiómica: volumen tumoral de mayor realce, para ser usada en vez de volumen tumoral funcional, para la predicción de la recurrencia y SLE. Así que se realizó un ensayo retrospectivo con secuencias sin y con contraste antes y después del primer ciclo que quimioterapia neoadyuvante, resultando ser un predictor de recidiva precoz, con la ventaja de ser calculado automáticamente y en tiempo real(10).

\section{3) Radiómica y Factores pronósticos:}

-Metástasis en ganglios linfáticos: es imprescindible en el estadiaje la valoración de la afectación axilar. Las investigaciones radiómicas han valorado estadísticos de orden superior (textura), encontrando relación significativa con la afectación ganglionar, en imágenes de RM en secuencias potenciadas en T2 con supresión grasa y difusión (9). 
-Grasa periturmoral: Los autores encontraron una relación significativa entre el análisis de la grasa peritumoral, extraída de la RM preoperatoria y afectación axilar, en pacientes con IMC superior a 30. La grasa peritumoral se define como el ratio de la grasa adyacente a la zona del tumor, un $1 \mathrm{~cm}$ peritumoral, frente al total de la grasa de la mama afecta. A pesar de la pequeña muestra de tamaño, los resultados sugieren que en estadíos iniciales la valoración de la grasa peritumoral se correlaciones significativamente con la extensión de la enfermedad a nivel axilar, sin necesidad de pruebas invasivas.(11)

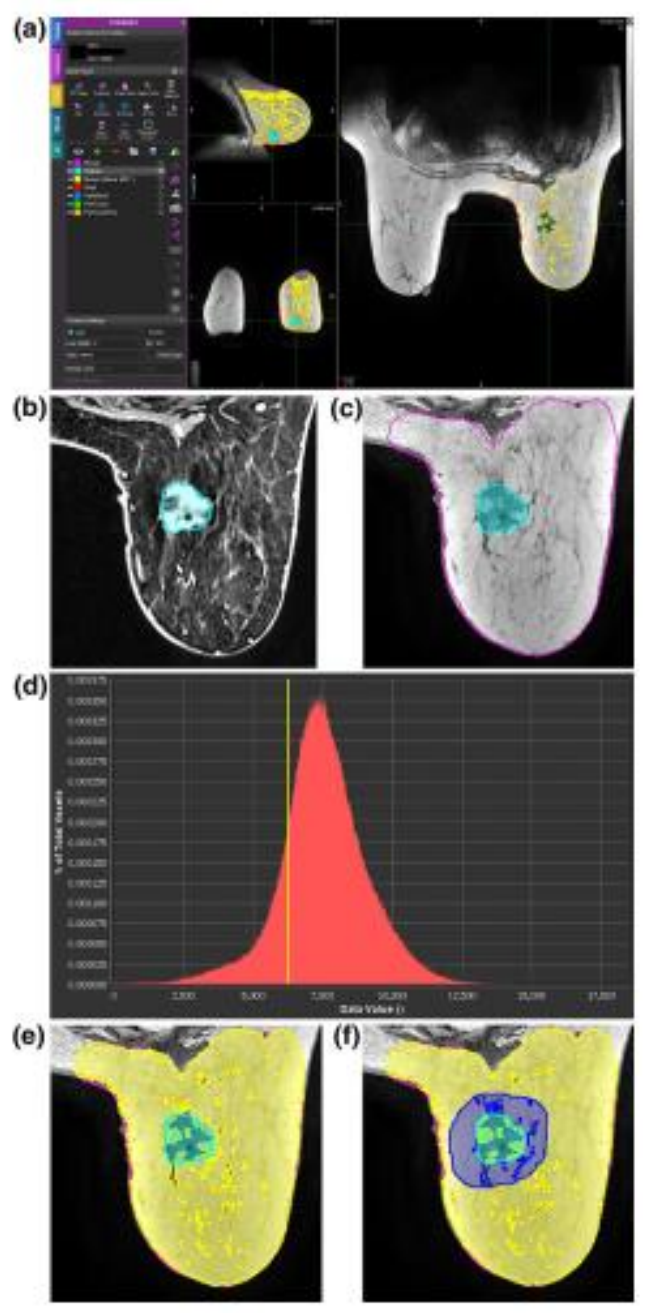

Figura №5: a. Se muestran imágenes de RM en plano axial, sagital y coronal en secuencias potenciadas en T1 en paciente con cáncer de mama. b. Contorno tumoral identificado en secuencia dinámica con contraste. c. Contorno tumoral en secuencia T1. d. Histograma de distribución de intensidades del voxel en T1. e. Secuencia T1 con zona de grasa marcada en amarillo. f. Generación de volumen/ ratio de grasa peritumoral, $1 \mathrm{~cm}$ adyacente al tumor (11). 
-Ki67: un nuevo marcador de radiómica, obtenido con la secuencia de resonancia magnética preoperatoria, podría predecir la expresión de Ki67 en la mama neoplásica a base de 30 características radiómicas, entre las que destacan: parámetros morfológicos, estadísticos de orden superior (textura)(10)

- El realce heterogéneo del tejido adyacente al cáncer de mama puede estar asociada con una respuesta inflamatoria y tiende a tener un pronóstico desfavorable.

Se estudió la zona peritumoral, creando un mapa radiogenómico, a través de descriptores cinéticos y estadísticos de primer orden, junto con secuencias de RNA del parénquima adyacente. Se identificaron características de la imagen con modelos de genes, como el de Factor de Necrosis tumoral (TNF), que se asociaba a peor pronóstico (12).

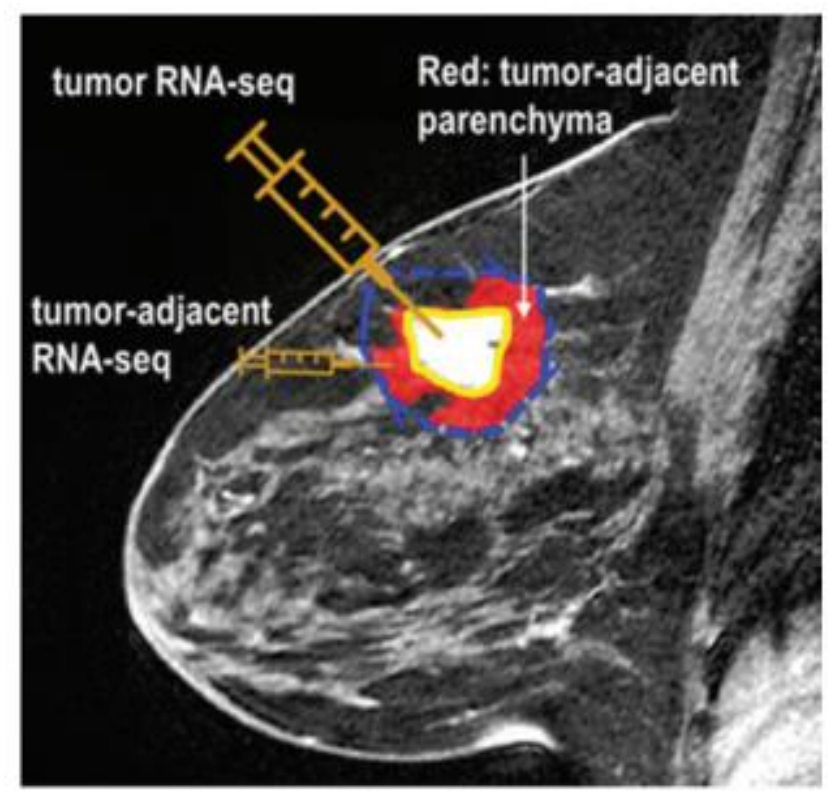

Figura №6: Imagen sagital, de la secuencia de sustracción de RM de mama con contraste donde se muestra el protocolo de adquisición para datos de secuenciación de ARN tumoral y parenquimatoso (RNASeq) en TCGA. El parénquima adyacente al tumor se define como la región roja, donde la línea amarilla es el límite del tumor y la línea azul punteada es el límite del tumor de $2 \mathrm{~cm}(11)$. 
4) Radiómica y respuesta a quimioterapia adyuvante; el tratamiento adyuvante reduce el tamaño tumoral y las metástasis a distancia, y es realizado en la primera línea de tratamiento para las pacientes diagnosticadas de un cáncer de mama localmente avanzado. Aunque menos del $50 \%$ de las pacientes obtienen una respuesta patológica completa. Se realizó un estudio retrospectivo sobre la capacidad de la radiómica para predecir la respuesta patológica completa, con resultados significativos, separando los grupos con $\mathrm{RH}+$ y HER - y TN y valorando los descriptores cinéticos y los estadísticos de primer orden, concluyendo que mostraba mayor eficacia en la zona peritumoral $(10,11)$.

5) Subtipos moleculares: Aplicando los modelos moleculares, se ha podido asociar los hallazgos en distintas modalidades de imagen con el tumor:

-RM: Se observó que los cánceres Luminales $A$, tenían bajos valores en las características relacionadas con la heterogeneidad tumoral (descriptores regionales), relacionadas con mejor pronóstico. Además, el subtipo de HER2 positivo, mostraba los valores de realce más altos, probablemente debido a su elevada angiogénesis y agresividad.

Así mismo, la radiómica, según los estudios, podría categorizar el subtipo TN mediante valoración del tumor y el tejido peritumoral, según imágenes de RM con contraste, a través del realce heterogéneo del parénquima y su textura (1)

-La Radiogenómica, podría determinar el subtipo tumoral, analizando la relación entre el realce del tumor y del parénquima de fondo. Los estudios han demostrado que las lesiones con mayor ratio de realce tumoral frente al realce de fondo se han relacionado con el subtipo Luminal B (14). 

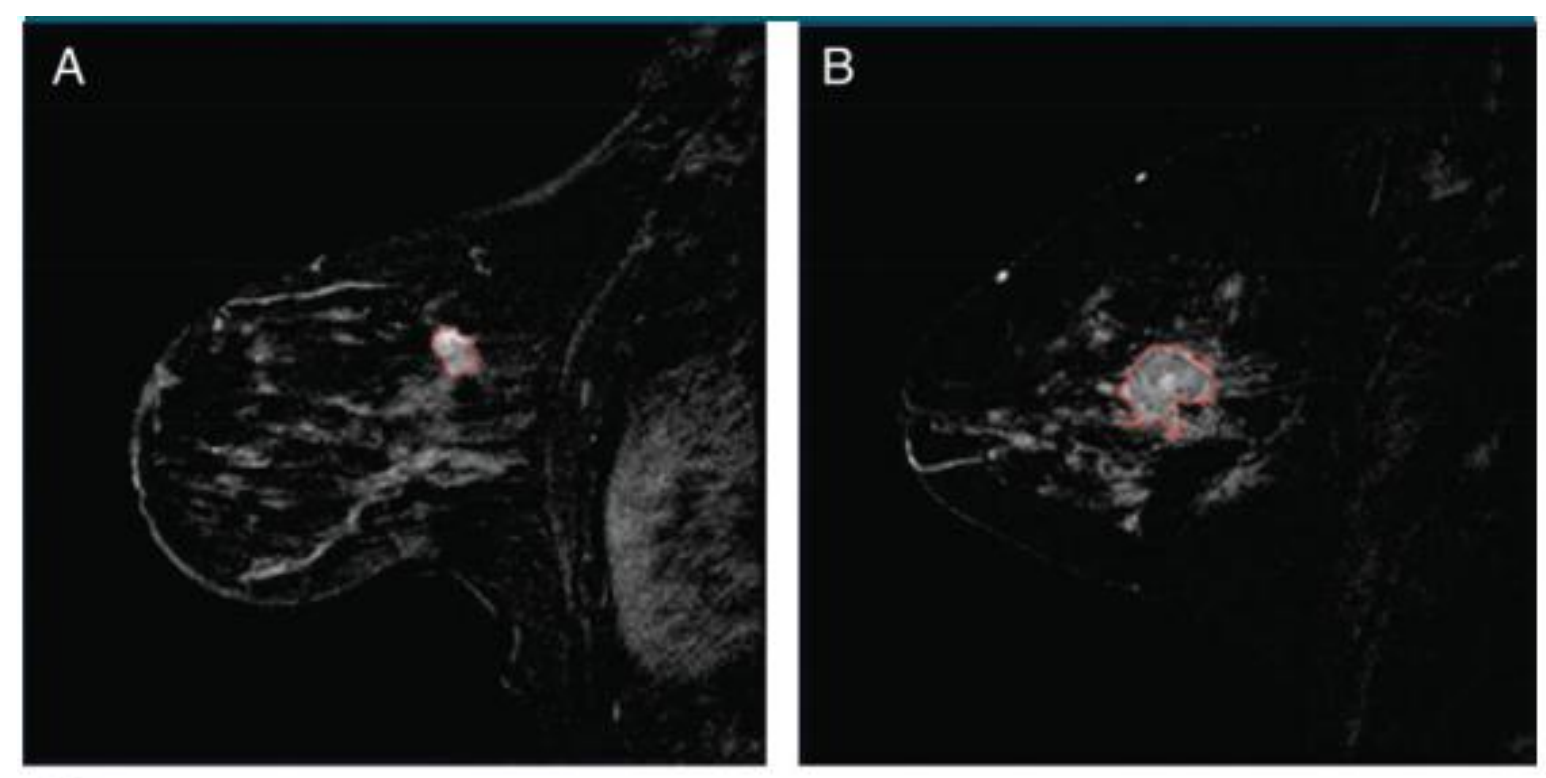

C

\begin{tabular}{|c|c|c|}
\hline & ER Positive Case (a) & ER Negative Case (b) \\
\hline Cancer Subtype & Luminal A & HER2-enriched \\
\hline $\begin{array}{c}\text { MRI CEIP Size } \\
\text { (Effective Diameter) } \\
\text { Range [7.8 54.0] }\end{array}$ & $12.9 \mathrm{~mm}$ & $23.8 \mathrm{~mm}$ \\
\hline $\begin{array}{c}\text { MRI CEIP Shape } \\
\text { (Irregularity) } \\
\text { Range [0.40 0.84] }\end{array}$ & 0.452 & 0.602 \\
\hline $\begin{array}{c}\text { MRI CEIP } \\
\text { Enhancement Texture } \\
\text { (Entropy) } \\
\text { Range [6.00 6.59] }\end{array}$ & 6.30 & 6.46 \\
\hline
\end{tabular}

Figura №7: Ilustración de la segmentación en el caso A, tumor RE positivo y B, tumor RE negativo. La segmentación del tumor y el análisis se muestra en $\mathrm{C}$, donde se extrae el fenotipo con los valores para tamaño, irregularidad y heterogeneidad en el realce con contraste (3).

-Ecografía y mamografía digital: Se valoran los márgenes, forma, límites, calcificaciones lineales ramificadas, ecogenicidad y patrón acústico posterior. Los tumores más irregulares, hipoecoicos, presentaron negatividad para Her2 y receptores hormonales positivos. De forma contradictoria los de forma regular, hipoecoicos o ecogenicidad compleja, resultaron ser TN. El patrón ecográfico fue el más efectivo en la predicción del subtipo molecular (9). Los biomarcadores de la mamografía digital, podría proporcionar a los clínicos información cuantitativa y cualitativa, con esquemas de aprendizaje de bases 
de datos, asistido por ordenador, según clasificaciones moleculares: Her 2+, Her 2- y luminal vs no luminal (10).

6) Valoración de riesgo de Cáncer: Los primeros estudios con portadoras de BRCA1 y BRCA2 (8) demostraron que las medidas de los descriptores estadísticos de orden superior, textura parenquimatosa ,mamográfica de la región retroareolar, medidas por ordenador, puede distinguir a los portadores BRCA1 / 2 de bajo riesgo. Otros estudios recientes de las poblaciones de detección también han demostrado que la textura del parénquima (ya sea de la región retroareolar o en otra área de la mama) están significativamente asociadas con el riesgo de cáncer de mama independiente de la densidad mamaria, sin embargo, no se han realizado estudios hasta la fecha para definir distintos fenotipos de imagen que reflejen la complejidad del tejido mamario.

Por otro lado, los fenotipos mostraron asociación significativa con cáncer de mama, mejorando la estimación del riesgo de cáncer de mama si se valora la densidad mamaria con el IMC (9).

\section{Perspectivas de futuro y retos:}

A pesar de toda la relevancia de las investigaciones sobre los descriptores estadísticos de orden superior, como la textura y los descriptores regionales, como la heterogeneidad, en su utilidad para el pronóstico, recurrencia, metástasis y respuesta a tratamiento, en el cáncer de mama las aplicaciones propuestas de la radiómica en la práctica clínica están limitadas. La falta de conocimientos de los conceptos básicos de los radiólogos y la limitada disponibilidad de sistemas eficientes y estandarizados de las características de extracción y de compartir datos, limita su uso e implantación (10).

Todavía falta por realizar más estudios en el entorno radiogenómico, dado que la mayoría de los estudios disponibles son retrospectivos y presentan un tamaño muestral pequeño y por lo tanto las conclusiones que pueden extraerse son algo limitadas.

Además, hay actualmente otras técnicas de imagen funcional de RM, como el sodioimagen (23Na-MR imagen), intercambio de saturación química de transferencia o CEST, imágenes de nivel de oxígeno en sangre dependiente o BOLD, imágenes por RM, así 
como tomografía de emisión de positrones híbrida / imágenes por RM, donde diferentes radiotrazadores están bajo investigación (3).

Estudios prospectivos más amplios están justificados, para poder definir qué asociaciones de radiómica y radiogenómica pueden realizarse de manera significativa en la rutina clínica (3). 


\subsection{Radiómica y Radiogenómica Cáncer de pulmón}

El cáncer de pulmón es el responsable de una gran proporción de muertes relacionadas con el cáncer por todo el mundo, siendo quizás el factor más relevante para su alta tasa de mortalidad, el retraso en el diagnóstico.

Aunque su prevalencia argumenta un programa de cribado en población de riesgo, la puesta en práctica del mismo no ha sido exitoso por el diagnóstico de lesiones benignas como malignas y creando una gran demanda de recursos (4).

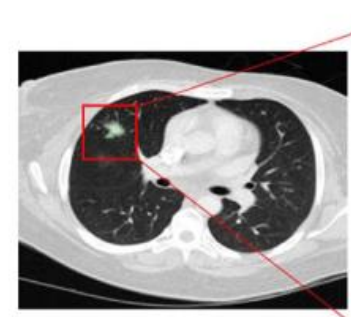

Benign Granuloma on CT

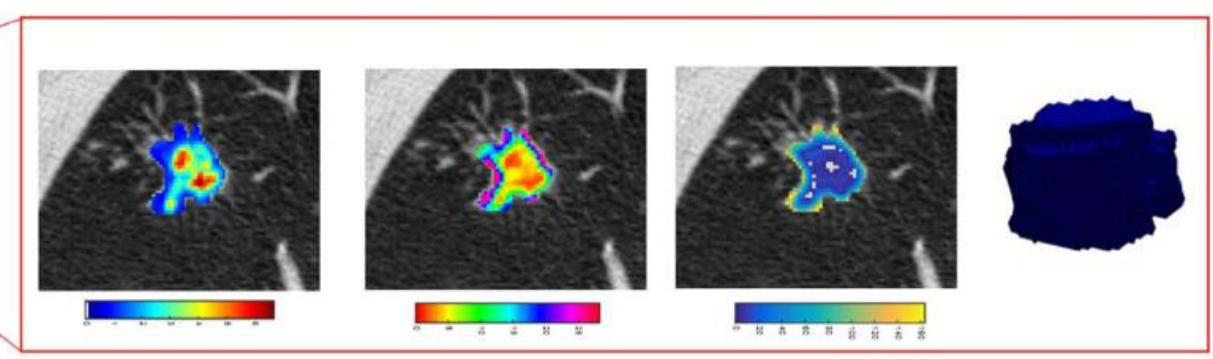

Haralick Correlation

Gabor

Shape

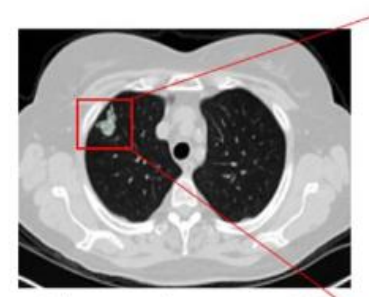

Adenocarcinoma on CT
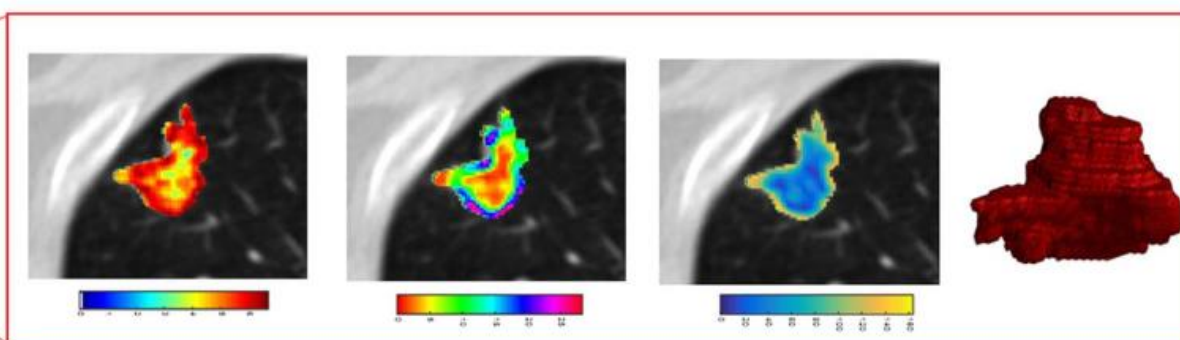

Figura N.. 8 :La primera línea representa un granuloma, mientas que la segunda muestra un caso maligno de adenocarcinoma en TC. Diferentes características radiómicas, basadas en textura y forma, pueden ayudar a diferenciar entre lesiones benignas y malignas. Valores bajos de Entropía, se ven en el granuloma en comparación con los altos valores de Entropía del adenocarcinoma. Haralick, representa la alta heterogeneidad, de la lesión maligna. Así mismo, el granuloma tiene una forma redondeada en comparación con el adenocarcinoma, que presenta un contorno irregular (15). 
Actualmente los hallazgos de la radiómica pueden dividirse en 4 grandes clases:

A Morfológicos: forma y volumen del tumor, como por ejemplo área de superficie y relación volumen/superficie. En términos de ratio superficie-volumen, el mayor ratio indica mayor espiculación e irregularidad del tumor, mientras que el menor ratio indica un límite más circunscrito. El volumen tumoral, en un parámetro importante en el cáncer de pulmón y, si aumenta el doble, se relaciona con mayor agresividad histológica y peor pronóstico. Se asume que el tumor es esférico pero la mayoría son irregulares. En radiómica, el volumen tumoral es determinado por el número de vóxeles en el ROI y multiplicándolo por el volumen del voxel, siendo más aproximado a la realidad del tumor. Así mismo, la masa tumoral, es un parámetro que integra volumen y densidad, una característica muy importante, dado el amplio espectro de manifestaciones del adenocarcinoma de pulmón, como los nódulos subsólidos o las opacidades en vidrio deslustrado. La medida de la masa tumoral y el crecimiento, es detectada más precozmente por la radiómica que con las medidas convencionales.

\section{B. Estadísticos:}

1. De Primer orden: características del histograma. Estadísticos de primer orden: entropía y energía, los más usados, media, mediana, desviación estándar, curtosis, oblicuidad, uniformidad y varianza, pueden ser generados de un histograma. Se pueden usar para diferenciar entre nódulo benigno y malignos. Tradicionalmente la evaluación de respuesta se realizaba con el tamaño tumoral, pero si la lesión se cavita, se necrosa o sangra, no se corresponde con reducción del tamaño. La mayor limitación de los histogramas es la pérdida de la información espacial de cada voxel. En general, las características radiómicas pueden aportar información adicional de la invasión y progresión tumoral e incluso predecir el crecimiento tumoral.

2. Alto orden: características de textura: pueden conservar la información espacial de los pixeles. La más usada es la matriz de escala de grises concurrente (GLCM), que analiza: correlación, clúster(racimos), contraste, energía y entropía.

Las características de textura se han usado ampliamente en CT y PET torácico. Muchos estudios han demostrado que las características de textura están asociadas con el estadio tumoral, metástasis, respuesta y supervivencia en 
cáncer de pulmón, resultando ser indicadores pronósticos en la oncología torácica.

C. Regionales: se basan en variaciones en la intensidad entre regiones, valorando cuantas subregiones y con qué frecuencia ocurren en un tumor. Por lo tanto, en contraposición con las características de textura, se espera que las características regionales cuantifiquen la heterogeneidad subclonal más allá de la zona más cercana. La heterogeneidad intratumoral es reconocida como uno de los factores pronósticos más prometedores para predecir la supervivencia del paciente y las características regionales, como subtipo histológico, localización anatómica, metabolismo de la glucosa, hipoxia y angiogénesis, se correlaciones con el pronóstico.

D. Basados en modelos: son extraídas usando aproximaciones matemáticas como el modelo fractal (dimensión fractal) que se puede aplicar en el pulmón basados en su anatomía. Valora la forma intrínseca de un objeto, para así diferenciar la agresividad del tumor. La dimensión fractal describe el grado de irregularidad de una superficie, donde las estructuras más irregulares tienen una mayor dimensión fractal. Se han utilizado estas características para estimar la

agresividad de los tumores por correlacionándolos con el estadio tumoral y SUVmax en las exploraciones $\operatorname{PET}(15,16)$. 


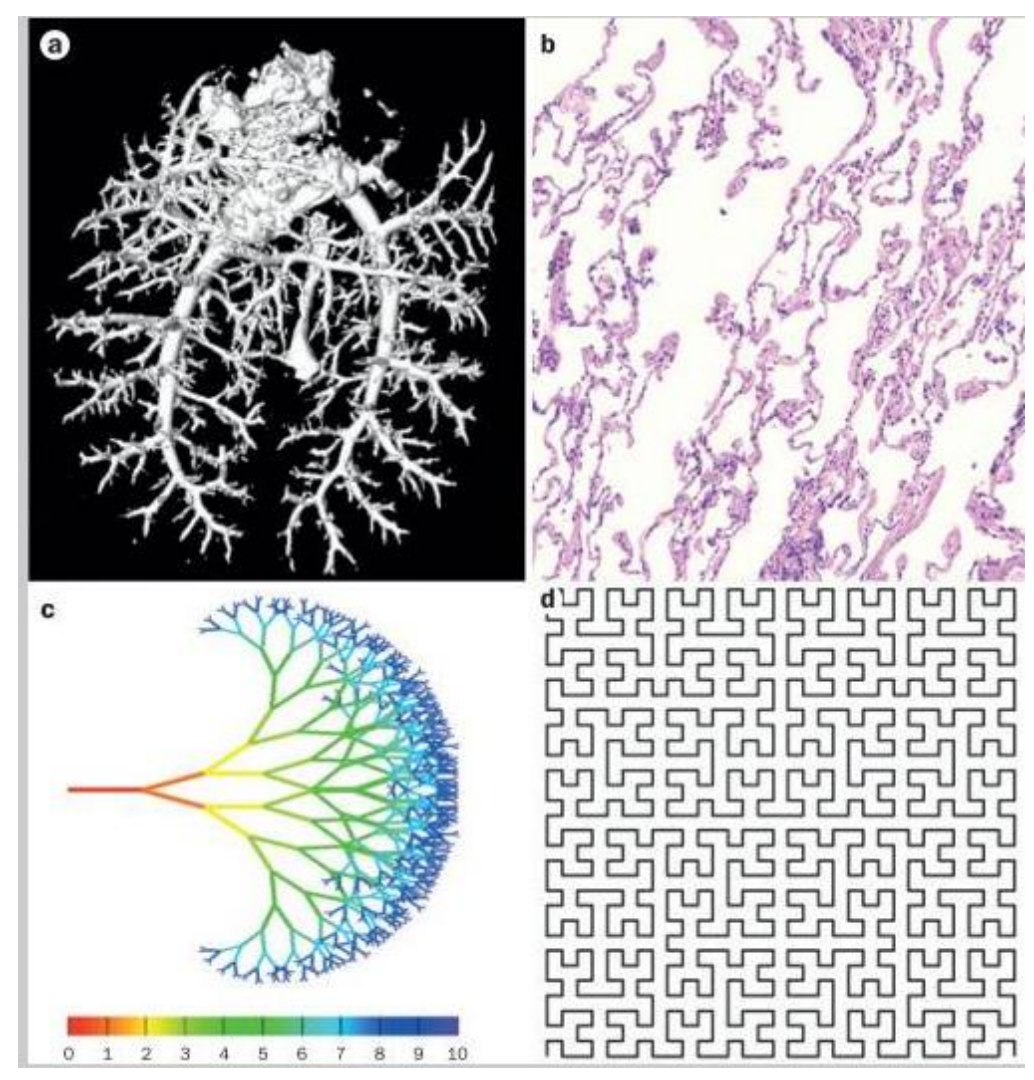

Figura N. 9: Ejemplos de patrones fractales biológicos y matemáticos. Los fractales biológicos pueden ser estadísticamente auto-similares en un rango limitado de escalas, conocido como una ventana de escalado. a Representación de la vascularización arterial pulmonar obtenida mediante angiografía por TC con contraste, que es un ejemplo de un fractal biológico. b Muestra de tejido pulmonar normal teñido con hematoxilina y eosina, que también tiene propiedades fractales, y por lo tanto es susceptible de análisis de la dimensión fractal. En comparación con los fractales biológicos, los fractales matemáticos pueden ser infinitamente auto-similares, los ejemplos son los árboles fractales $(\mathrm{C})$ y la curva de Hilbert (d) (16).

Además, recientemente se ha sugerido como un nuevo método de análisis de la textura de la imagen el método de la disimilaridad en el modelo fractal. Estudiando la heterogeneidad en la captación dinámica del contraste, se podría monitorizar la respuesta precoz a al tratamiento antiangiogénico (4). 
Cada categoría, tiene una serie de campos que reflejan aspectos específicos del tumor. El mayor desafío consiste en integrar los hallazgos de la radiómica con los clínicos, patológicos e información genética, para descodificar los tipos de tejidos biológicos (4).

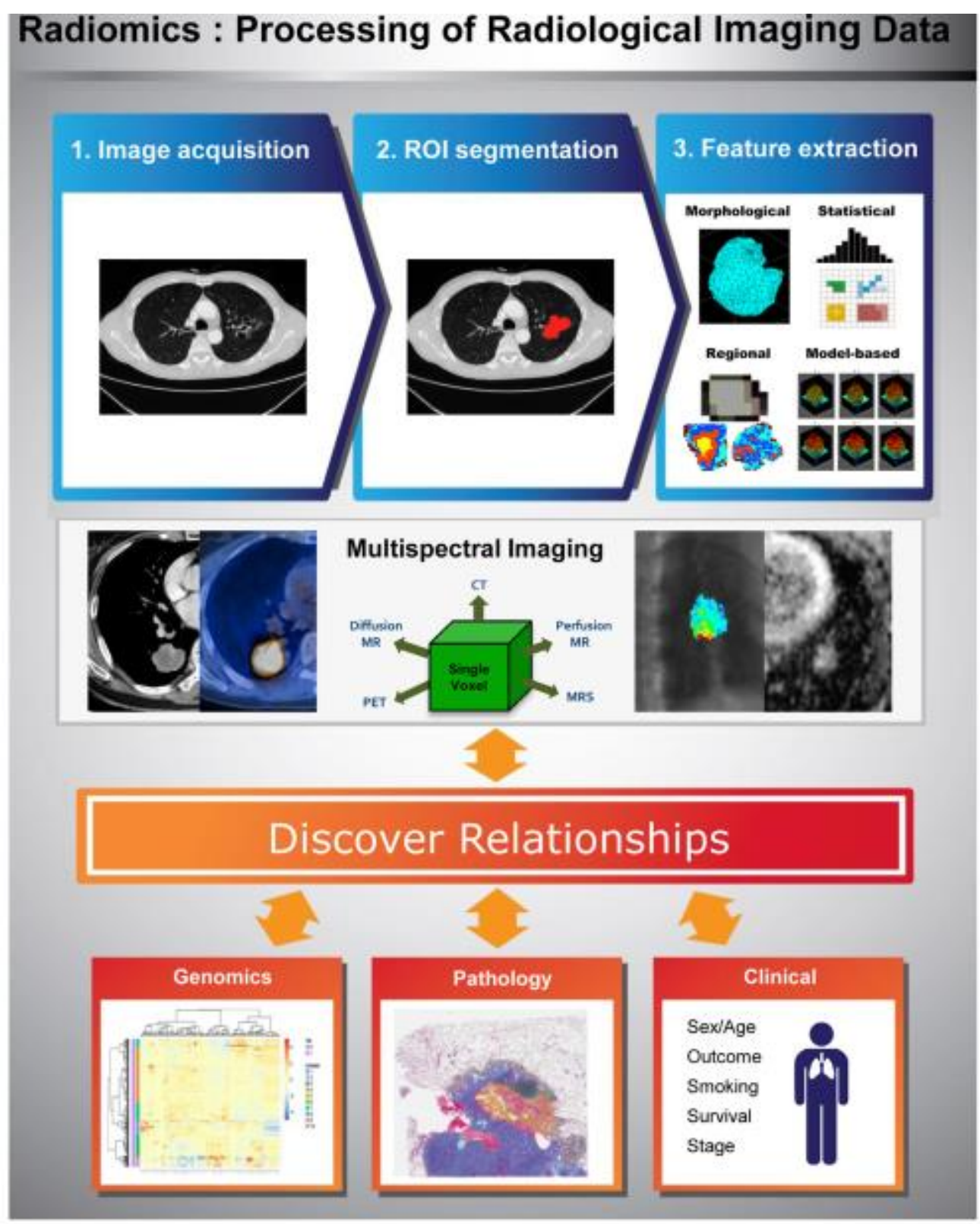

Figura no10: Visión general de la radiómica en el procesamiento de datos de imágenes radiológicas. Las regiones de interés están segmentadas para todo el tumor y se extraen múltiples características cuantitativas. La combinación de información de múltiples modalidades de imágenes proporciona una vista multiespectral del tumor y permite una 
mejor caracterización del tumor. Es un desafío y un importante paso descubrir las relaciones entre las características radiológicas, genómicas, patológicas y clínicas (4).

Aplicaciones de la radiómica: Las características que se usan para el análisis son: descriptores morfológicos, estadísticos de orden superior (textura) y regionales (intensidad).

-Cribado de cáncer de pulmón, con el fin de maximizar la sensibilidad y especificidad, para disminuir la carga asistencial de los radiólogos.

-Predictor de respuesta a ciertas terapias en el campo de la medicina de precisión (4)

-Marcadores Pronósticos: Las investigaciones han evidenciado asociación con el pronóstico de cáncer de pulmón, estadio, histología e incluso con metástasis a distancia. La textura, detecta la heterogeneidad del nódulo que se ha correlacionado con la agresividad del tumor y con el mal pronóstico del cáncer. Para el radiólogo, analizar la heterogeneidad es subjetivo y dificultoso, por eso el análisis de la textura, asistido por ordenador permite un método más objetivo para cuantificar esta importante característica pronostica (15).

-Predicción afectación metástasis ganglionares: La afectación de los ganglios linfáticos en el cáncer de pulmón, es importante para el pronóstico y la recidiva. Por eso es vital diseñar una técnica no invasiva, preoperatoria que nos evalúe correctamente el estadiaje tumoral de los cánceres de pulmón de células no pequeñas, para el planteamiento quirúrgico y pronóstico.

Normalmente se usa el Tc: tamaño, morfología, necrosis o invasión externa de la cápsula, pero todo esto es poco preciso, sólo el PET-Tc muestra mayor precisión y alta especificidad, pero su baja disponibilidad y alto coste, limita su aplicabilidad en la clínica.

La radiómica valorando la textura, ha demostrado en los estudios, la capacidad discriminatoria de afectación ganglionar en pacientes con adenocarcinoma de pulmón (17).

La radiogenómica, permite relacionar las características de la imagen con alteraciones genómicas del ADN, permitiendo diagnosticar la presencia de mutaciones específicas que crean alteraciones biológicas que afectan a la respuesta en tratamientos en ciertos pacientes (4). 
Aets et al, aplicaron este concepto para el cáncer de pulmón, describiendo que la extracción pretratamiento, de los datos del TC, podría diagnosticar estados de mutación del EGFR y la respuesta tumoral al tratamiento con Gefitinib. Ellos usaron una mezcla de descriptores que incluían el volumen, textura y gradiente, para estimar la presencia de esta mutación (15).

Futuro próximo: Desde que el CT está ampliamente siendo empleado en la práctica clínica para los pacientes con cáncer de pulmón, la radiómica debe ser una herramienta fácil para ver e interpretar el comportamiento bilógico de los tumores. La estandarización para la adquisición de parámetros, usando los métodos de la radiómica y mejorando la reproductibilidad, están siendo los objetivos para validar los modelos de clasificación. Además, se debe explorar la exactitud de la interpretación asistida por ordenador junto a los radiólogos, para mejorar el diagnóstico, disminuir los costes y el tiempo empleado por los radiólogos en cada exploración.

Las investigaciones de radiómica, en el futuro, mejorarán la utilidad de la imagen médica, haciendo de esta una poderosa herramienta para dar información respecto al diagnóstico, terapia individualizada, supervivencia y pronóstico.

Es importante reseñar que la radiómica no quiere reemplazar a los radiólogos en el diagnóstico del cáncer de pulmón, es una herramienta para diagnosticar y caracterizar con gran precisión y ayudará a otros profesionales a individualizar tratamientos para sus pacientes (15). 


\subsection{Radiómica y Radiogenómica en GBM}

Los GBM son tumores cerebrales primarios más frecuentes y altamente vascularizados (18). Presentan mal pronóstico, con una media de supervivencia de 12-15 meses a pesar de la cirugía seguida de quimioterapia concurrente con temozolomida y radioterapia (19). Esto ha hecho que se investigue los posibles factores pronósticos del GBM. Varios factores pronósticos pueden influir en la supervivencia de los pacientes con GBM, incluyendo características clínicas, moleculares (delección de los brazos de los cromosomas 1 p y 19 q, mutación de la isocitrato deshidrogenasa IDH1 y de $\mathrm{O} 6$ metilguanina-ADN metiltransferasa MGMT).

Las mutaciones de la IDIH1 se relaciones con gliomagénesis y se considera un indicador independiente de buen pronóstico. El silenciamiento epigenético, mediante la metilación de la enzima reparadora del AND MGMT, se asocia con mejor respuesta a la terapia con Temazolamida y con mejor pronóstico que cuando no está Desmetilada (19).

\section{Aplicaciones de la radiómica:}

1) Valoración supervivencia:

Se han realizado múltiples estudios, valorando, si los hallazgos de la radiómica podrían predecir la supervivencia y clasificar a los pacientes diagnosticados de GBM, con mayor fiabilidad que con los modelos de riesgo clínicos y radiológicos.

En estadios iniciales, se valoraron 11 parámetros radiómicos de la RM con contraste, seleccionado para el modelo final exclusivamente en FLAIR de la porción del tumor realzada. Se estudiaron los estadísticos de primer orden (histogramas: media, mediana, desviación estándar, kurtosis, oblicuidad, energía, entropía, uniformidad y varianza), descriptores morfológicos y estadísticos de orden superior ( textura), analizándolos junto a la supervivencia global (OS) y supervivencia libre de progresión (PFS).

El nivel de grises, basado en la matriz de coocurrencia "Desviación estándar de la energía", derivada de una transformación ondícula no decimada, tuvo la puntuación de importancia más alta (negativa) que influyó en el modelo, relacionado con peor supervivencia. Estos parámetros reflejan la heterogeneidad del tumor, en la que la elevada variabilidad del parámetro de la energía muestra la combinación de la variación de los valores de la escalada de grises con la distribución del histograma. 
El estudio mostró asociación entre los parámetros radiómicos y los datos de supervivencia, aunque se tendrán que validar dichos modelos de riesgo, para clasificar a los pacientes según la supervivencia, en futuros estudios (17).

2) Fenotipage GBM previo a cirugía:

La mayoría de los pacientes con GBM se someten a cirugía como parte del tratamiento estándar y la información de pronóstico multinivel, incluidos los estados de MGMT e IDH1 y los perfiles clínicos, se conocen después de la cirugía. Se han realizado estudios de radiómica, estudiaron 18 parámetros radiómicos, extraídos de RM multiparamétricas, para valorar su poder de fenotipar los GBM aportando información pronostica, independiente de la clínica y de la información genética (19).

Se estudiaron 9 parámetros de textura, 7 de la forma del tumor y dos de primer orden, en imágenes de RM con contraste con secuencias potenciadas en T1, T2 y Flair. La textura aportó información sobre la heterogeneidad tumoral. La intensidad en del tumor tras el contraste en secuencias potenciadas en T1, T2 y Flair, se relacionó con el grado de celularidad e incluso el realce postcontraste en secuencias potenciadas en $\mathrm{T} 1$, se relacionó con la agresividad histopatológica del tumor, causada por la disrupción de la barrera hemato-encefálica.

Esto implica que la radiómica tiene un potencial como biomarcador de imagen en el estadiaje clínico mejorando la clasificación y personalizando el tratamiento en los pacientes con GBM.

El fenotipado radiológico puede mejorar la predicción de supervivencia cuando se integra con la clínica y la genética (19). 


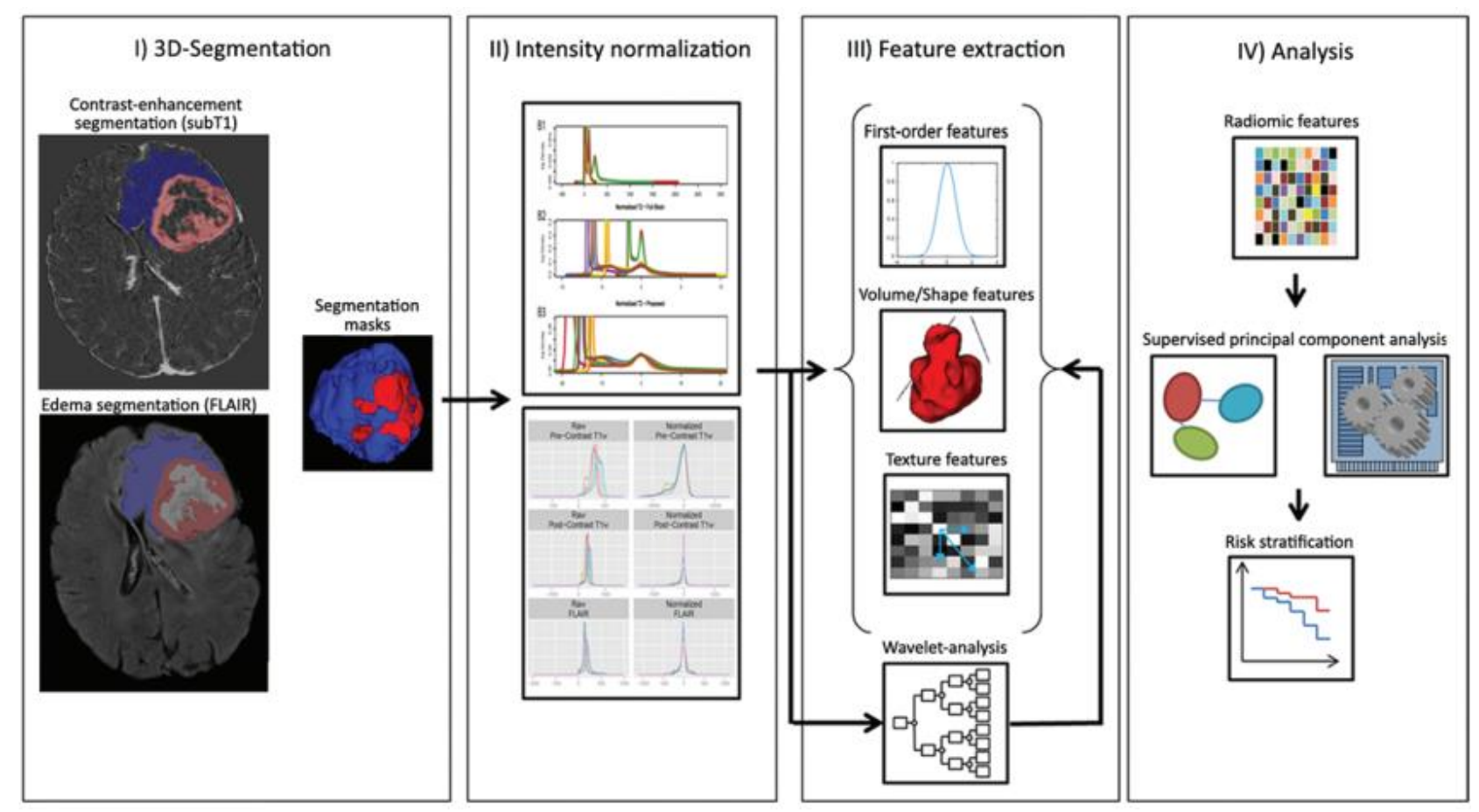

Figura N. 11: Esquema de trabajo de flujo radiómico. Los tumores tienen diferentes formas y niveles de intensidad, como se muestra en las imágenes. En la izquierda, se muestra la segmentación del tumor en rojo, en una reconstrucción volumétrica en 3D. De la segmentación pasamos al análisis estadístico de la izquierda a la derecha.

I: segmentación en RM, tanto en secuencia potenciada en T1 con contraste, como en secuencia FLAIR.

II: imágenes de niveles de intensidad normalizados en parámetros de espacio que permiten referencia de diferentes características.

III: Múltiples características radiómicas, calculadas automáticamente desde las imágenes de RM, en secuencia T1 con contraste y FLAIR con intensidad normalizada, usando la segmentación y analizando los estadísticos de primer orden, volumen y forma y características de textura. Además, se realiza una descomposición en 3D wavelet.

IV: Obtención de un gran número de parámetros radiómicos son analizados, asistidos por modelos de aprendizaje, para realizar una estratificación de riesgo (18). 
Radiogenómica: la caracterización genómica del GBM ha mejorado el asesoramiento clínico. Así mismo el descubrimiento de un mapa radiogenómico, tiene el potencial de abordar la necesidad clínica de biomarcadores sustitutos que puedan predecir con precisión la biología del tumor subyacente y la respuesta de la terapia en GBM.

Se demostró que la radiogenómica, utilizando parámetros de la imagen cuantitativos, presentaba relación significativa con la supervivencia, subtipos moleculares y los criterios VASARI.

Por otro lado, se mostró el poder de crear mapas radiogenómicos usando Amaretto (algoritmo de fusión de datos ómicos para identificar genes conductores de cáncer) y el modelo expresión de genes para indirectamente asociar las características de la imagen con el proceso bilógico subyacente (20).

Hasta la fecha, múltiples estudios han demostrado asociación entre las características moleculares y las de la imagen incluyendo, localización tumoral, volumen tumoral, realce, infiltración, edema y restricción a la difusión.

Recientemente se ha descubierto la heterogeneidad tumoral, consecuentemente, se deben crear predictores moleculares, usado la radiogenómica para el seguimiento de los pacientes y los tratamientos evitando las biopsias múltiples en los tumores cerebrales.

Se identificaron biomarcadores moleculares predictivos o Clusters epigenómicos por medio de la función de imágenes de RM multidimensional, como la amplificación del EGFR pero con escasa consistencia para crear modelos clasificadores de predicción asistidos por ordenador.

Por otro lado, no se vio que hubiera predilección de localización para las diferentes anomalías moleculares, como MGMT, microarrays de metilación del ADN y EGFR (21). 


\section{7-CONCLUSIÓN:}

-Existen investigaciones que apoyan la utilidad de la radiómica y radiogenómica, aunque también existen limitaciones, como son la pérdida de estandarización de la adquisición de los parámetros, la inconsistencia del método y la ausencia de reproductibilidad, que impiden su aplicación clínica.

-Se han visto evidencias en la investigación en la información que aportan los descriptores morfológicos, estadísticos (textura y entropía), regionales (heterogeneidad) y dinámicos, en cuanto al pronóstico y recurrencia de la enfermedad.

-Existe un gran potencial de su futuro en su aplicación en oncología clínica, pasando a una medicina de precisión, personalizada, basada en métodos biológicos.

-La radiómica puede ser un soporte importante para el diagnóstico.

-La radiogenómica, actualmente, se usa sólo para identificar la correlación, no la causa y no puede reemplazar al análisis genético del tejido. Aunque en el futuro próximo, se podrá utilizar una sola prueba tanto el diagnóstico, como pronóstico, determinar factores de riesgo y seleccionar el mejor tratamiento personalizado, evitando la comorbilidad asociada a las biopsias. 


\section{BIBLIOGRAFÍA}

1- Hidetaka A, Mazen S, Hidemi K, Kenta N, Masahiro Y.

Radiomics with artificial intelligence for precision medicine in radiation therapy.

J. Radiat Res. 2019; 60(1): 150-57.

2- Martí Bonmatí L, Alberich-Bayarri A, García-Martí G, Sanz Requena R, Pérez Castillo C, Carot Sierra J.M. y Manjón Herrera J.V.

Biomarcadores de imagen, imagen cuantitativa y bioingeniería.

Radiología. 2012;54(3):269-78.

3- Pinker K, Chin J, Melsaether A.N, Morris E.A, Moy L.

Precision Medicine and Radiogenomics in Breast Cancer: New apporaches toward Diagnosis and Treatment.

Radiology. 2018;287(3):732-47.

4- Lee G, Lee HY, Park H, Schiebler ML, van Beek EJR, Ohno Y, Beom J, Seo JB, Leung A.

Radiomics and its emerging role in lung cancer research, imaging, biomarkers and clinical management.

Eur J Radiol.2017;86: 297-307.

5- Li H, Zhu Y, Burnside ES, Drukker K, Hoadley KA, Fan C, Conzen SD, Whitman G J, Sutton EJ , Net J M, Ganott M, Huang E, Morris E A, et al.

Mr Imaging Radiomics Signatures for predicting the Risk of Breast Cancer Recurrence as Given by Research versions of MammaPrint, Oncotype Dx, and PAM50 Gene Assays Radiology.2016; 281(2): 382-391.

6- Li H, Mendel KR, Lan L, Sheth, D, Giger ML.

Digital Mammography in Breast Cancer: Additive Value of Radiomics of Breast Parenchyma.

Radiology. 2019; 291:15-20. 
7- Tagliafico AS, Valdora F, Mariscotti G, Durando M, Nori J, La Forgia D, Rosenberg I, Caumo F, Gandolfo N, Houssami N, Calabrese M.

An exploratory radiomics analysis on digital breast tomosynthesis in women with mammographically negative dense breasts.

Breast.2018;40: 92-96.

8- Woodard G.A, Ray K.M Joe BN, Price E.R.

Qualitative radiogenomics: Association between Oncotype DX.

Test Recurrence Score and BI-RADS Mammographic and Breast MR Imaging Features Radiology. 2018;286 (1): 60-70.

9- Kontos D, Winham SJ, Oustimov A, Pantalone L,

Hsieh M.K, Gastounioti A,Whaley D.H, Hruska C.B, Kerlikowske K, Brandt Conant K, Vachon C.M.

Radiomic Phenotypes of Mammographic Parenchymal Complexity: Toward Augmenting Breast Density in Breast Cancer Risk Assessment.

Radiology. 2019; 290:41-49.

10- Crivelli P, Ledda RE, Parascandolo N, Fara A, Soro D, Conti M A New Challenge for Radiologists: Radiomics in Breast Cancer.

BioMed Res Int. 2018;8:1-10.

11- Obeid JP, Stoyanova R, Kwon D, Patel M, Padgett K, Slingerland J, Takita C, Alperin $\mathrm{N}$, Yepes M Zeidan YH.

Multiparametric evaluation of preoperative MRI in early stage breast cancer: prognostic impact of peri-tumoral fat.

Clin Tranl Oncol.2017;19(2):211-18 
12- Wu J, Li B, Sun X, Cao G, Rubin DL, Napel S, Ikeda DM, Kurian AR, Li R Heterogeneous Enhancement Patterns of Tumor-adjacent Parenchyma at MR Imaging Are Associated with Dysregulated Signaling Pathways and Poor Survival in Breast Cancer. Radiology. 2017;285(2):401-13.

13- Wang J, Kato F, Oyama-Manabe N, Li R, Cui Y, Tha K. K, Yamashita H, Kudo $\mathrm{K}$, Shirato $\mathrm{H}$

Identifying Triple-Negative Breast Cancer Using Background Parenchymal Enhancement Heterogeneity on Dynamic Contrast-Enhanced MRI: A Pilot Radiomics Study

PLoS One. 2015;10(11):1-17

14- Mazurowski M.A, Zhang J, Grimm L.J, . Yoon S.C, Silbe J.I.

Radiogenomic analysis of Breast cancer: Luminal B Molecular Subtype Is Associated with Enhancement Dynamics at MR Imaging.

Radiology. 2014;273(2):365-72.

15- Thawania R, McLaneb M, Beigb N, Ghoseb S, Prasannab P, Velchetic V, Madabhushi A.

Radiomics and Radiogenomics in lung cancer: A review for the clinician Lung Cancer.2018; 115 : 34-41.

16- Lennon F.E, Cianci G.C, Cipriani N.A, Hensing T.A, Zhang H.J, Chen C.T, Murgu S.D, Vokes E.E, Vannier M.W, Salgia R.

Lung cancer-a fractal viewpoint.

Nat Rev Clin Oncol. 2015; 12(11): 664-75.

17- Yang X, Pan X, Liu H, Gao D, He J, Liang W, Guan Y.

A new approach to predict lymph node metastasis in solid lung.

adenocarcinoma: a radiomics nomogram.

J Thorac Dis. 2018;10(Suppl 7):807-819. 
18- Philipp Kickingereder P, Burth S, Wick A, Götz M, Eidel O ,Schlemmer HP, MaierHein KH, Wick W, Bendszus M, Radbruch A,Bonekamp D.

Radiomical Profiling of Glioblastoma: Identifying an Imaging Predictor of Patient Survival with Improved Perdormance over Esablished Clinical and Radiologic Risk Models.

Radiology. 2016;280 (3):880-89.

19- Bae S, Choi, Y.S, Ahn S.S, Chang J.H, Kang S.G, Kim E.K, Kim S.H, Lee S.K.

Radiomic MRI Phenotyping of Glioblastoma: Improving Survival Prediction.

Radiology.2018; 289 (3):797-806.

20- Gevaert O, Mitchell L.A, Achrol A.S, Xu J , Echegaray S, Steinberg G.K, Cheshier S.H, Napel S, Zaharchuk, Plevritis S.K.

Glioblastoma Multiforme: Exploratory Radiogenomic Analysis by Using Quantitative Image Features.

Radiology.2014;273(1):168-74.

21- Philipp Kickingereder P, Bonekamp D, Nowosielski M, Kratz A, Sill M, Burth S, Wick A, Eidel O, Schlemmer HP, Radbruch A, Debus JMD, Herold-Mende C, Unterberg A, Jones D, Pfister S.

Radiogenomics of glioblastoma: Machine Learning-based Classification of Molecular Characteristics by Using Multiparametric and Multiregional MR Imaging Features.

Radiology.2016;281(3):907-18. 